\title{
Effect Of Flow Resistance In Open Rectangular Channel
}

\author{
Noor Aliza Ahmad ${ }^{1, *}$, Saiful Iswal Saiful Bahry ${ }^{2}$, Zarina Md Ali $^{2}$, Azra Munirah Mat \\ Daud $^{2}$, and Sabariah Musa ${ }^{2}$ \\ ${ }^{1}$ Faculty of Civil Engineering and Environmental, Department of Water Engineering and \\ Environment, University Tun Hussein Onn Malaysia,86400 Parit Raja,Batu Pahat,Johor,Malaysia \\ ${ }^{2}$ Faculty of Civil Engineering and Environmental, Department of Water Engineering and \\ Environment, University Tun Hussein Onn Malaysia,86400 Parit Raja,Batu Pahat,Johor,Malaysia
}

\begin{abstract}
The determination of flow resistance for open channels remains a challenge in practices. In this research, an experimental study was carried out to investigate the hydraulic roughness characteristics in an open channel. The experimental flume $(10 \mathrm{~m}$ length, $0.30 \mathrm{~m}$ width and 0.46 height) was carried out with two conditions ; contain gravel bed and without gravel bed (as controller). Blocks of concrete foam were fabricated and laid on the bed surface for providing uniformly roughened along the open channel. A velocity flow meter was used to quantify the average velocity, and other parameters such as cross-section, hydraulic radius, wetted perimeter, and channel slopes were also calculated. Finally, the flow resistance, $n$ obtained using the flume with gravel bed surface is higher than the flume without gravel bed surface. The flow conditions were declared as subcritical as the Froude number is less than 1 for both conditions in the flume. As a conclusion, it was identified that the hydraulic roughness $n$, was influenced by the type bed roughness, flow rate and channel slope.
\end{abstract}

\section{Introduction}

Open channel can be classified as either natural or artificial channel. The terminology natural channel refers to all channels which have been developed by natural processes and have not been significantly improved by humans. [1] An important characteristic of open channel flow is that it has a free surface at atmospheric pressure. [2]

The Manning formula has been widely used to determine the roughness coefficient, $n$ for open channels. The variation of roughness coefficient, $\mathrm{n}$ occurs due to many contributing factors such as surface roughness, channel irregularity, channel alignment, silting, vegetation, obstruction and flow rate [2]. Although the $n$ values have been practiced in hydraulic and hydrology analysis, the determination of $n$ is becoming a challenge to engineers and researcher because the values cannot be computed equally for all types of open channels [3].

* Corresponding author: aliza@uthm.edu.my 
In analyzing the flow through open channels of regular sectional shape and hydraulic roughness, in general, it is sufficientto use the overall hydraulic radius as the parameter, which characterizes the properties of the cross section [4]. It is then possible to calculate the discharge through the channel from one range of well-known formulas in term of the channel roughness, slope, and depth. Manning's equation was based on data from flume studies and developed for uniform flow conditions in which the water-surface slope, friction slope, and energy gradient are parallel to the stream bed, and the cross-sectional area, hydraulic radius, and depth remain constant throughout the reach.

The influence of bed roughness gives some effect to flow rate and the roughness characteristics [5]. Focusing on the experimental investigations for hydraulic roughness, [6], it used the particle image velocimetry to study the effects of roughness on the flow structure in a gravel bed channel. They established a new formula to calculate the friction factor for the gravel bed, expressed in terms of the Reynolds number and the surface geometric parameters.

This study has been carried out to analyze the effects of bed roughness to the velocity and determine the hydraulic roughness at roughened rectangular bed in open channel. All data were collected in a laboratory work at the Hydraulic Laboratory of the Faculty of Civil Engineering and Environmental, Universiti Tun Hussein Onn Malaysia (UTHM), Malaysia.

\section{Experimental apparatus and method}

\subsection{Sample material and model set-up}

Two blocks of lightweight concrete, which are formed by form agent with cement mixture was used in this experiment. The samples of the block with size $400 \mathrm{~mm}$ x $295 \mathrm{~mm}$ were prepared by adding the gravel and without gravel. Approximately, $50 \%$ of each gravel was submerged in the concrete foam. Three grades of gravel were used $(5-10 \mathrm{~mm}, 20-30 \mathrm{~mm}$, and $50-70 \mathrm{~mm}$ ) to create a single geometric and hydraulic roughness as shown in Figure 1. The blocks without gravel were functioning as a controller.

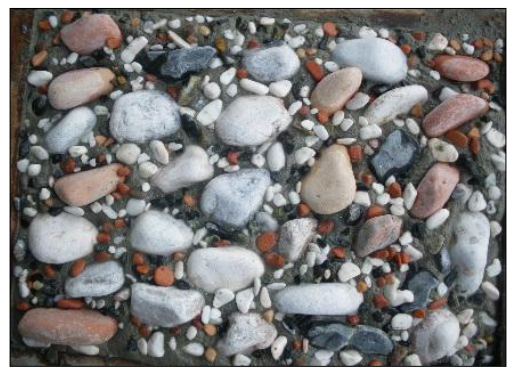

Fig.1. Gravel bed as a bed roughness in flume

The experiment was carried out in the Hydraulic Laboratory of the Faculty of Civil Engineering and Environmental, Universiti Tun Hussein Onn Malaysia (UTHM), Malaysia. It was accompanied in a flume of $0.30 \mathrm{~m}$ wide and $0.46 \mathrm{~m}$ deep with an overall $10 \mathrm{~m}$ long as in Figure 2. The flume was set to the slopes 1:500(0.002), 1:400(0.0025), and 1:300(0.0033) respectively. Block samples: lightweight concrete foam with gravel and without gravel, were placed on the bed along the open channel to provide a uniform 
roughness. Water was pumped into the flume from a circulation storage tank and each bed material was tested with 4 fixed discharges; $0.020 \mathrm{~m}^{3} / \mathrm{s}, 0.025 \mathrm{~m}^{3} / \mathrm{s}, 0.030 \mathrm{~m}^{3} / \mathrm{s}$, and 0.035 $\mathrm{m}^{3} / \mathrm{s}$ by adjusting the water pump valve, which can be opened and closed by a steel wheel. The flow depth and velocity were measured at three different points (Section I, II and III) by the current meter.

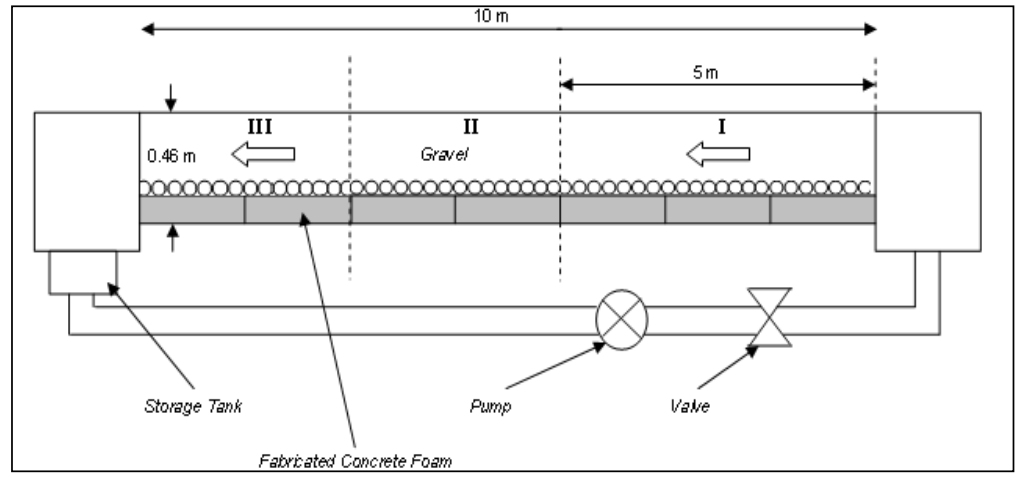

Fig. 2. Schematic diagram of flume with gravel

\section{Results and analysis}

\subsection{The discharge and the flow resistance coefficient}

Roughness coefficients represent the resistance to flows in channels and flood plains. The results of Manning's formula, an indirect computation of flow, have applications in flood plain management, in flood studies and in the design of bridges and highways across flood plains [7]. A channel roughness can be described through Manning roughness coefficient, $\mathrm{n}$ as stated in the equation (1) [2]:

$$
n=\frac{1}{Q} A R^{2 / 3} S^{1 / 2}
$$

$$
Q=A V
$$

Where; $\mathrm{Q}=$ fixed discharges $\left(\mathrm{m}^{3} / \mathrm{s}\right), \mathrm{A}=$ cross sectional area of flow $\left(\mathrm{m}^{2}\right), \mathrm{n}=$ Manning coefficient of roughness, $\mathrm{R}=$ hydraulic radius $(\mathrm{m}), \mathrm{S}=$ fixed bed slope, $\mathrm{V}=$ mean velocity $(\mathrm{m} / \mathrm{s})$

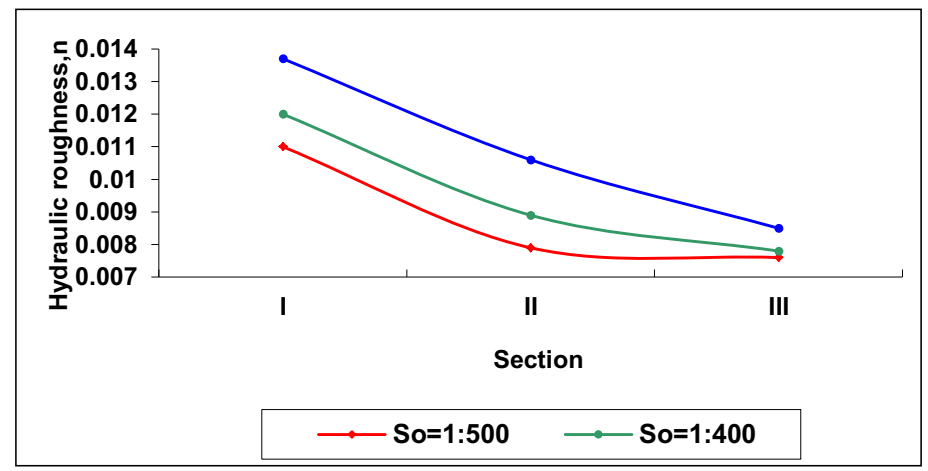

Fig. 3. Hydraulic roughness coefficient along three section with fixed discharges 
$0.025 \mathrm{~m}^{3} / \mathrm{s}$ with gravel bed.

Figure 3 and 4 present the flow resistance coefficient along the section I, II and III with gravel bed and without gravel bed and fixed discharges of $0.025 \mathrm{~m}^{3} / \mathrm{s}$ respectively. All data were performed in three different slopes; 1:300, 1:400, and 1:500. It showed the relation between the hydraulic roughness, $\mathrm{n}$ under fixed discharges and slopes for the tested bed materials (with gravel bed). Also, it was noticed that the maximum and minimum hydraulic coefficients were found in the case of gravel bed material. Consequently, it can be concluded that the hydraulic roughness coefficient inversely proportionally to the discharge, slopes and fixed bed material.

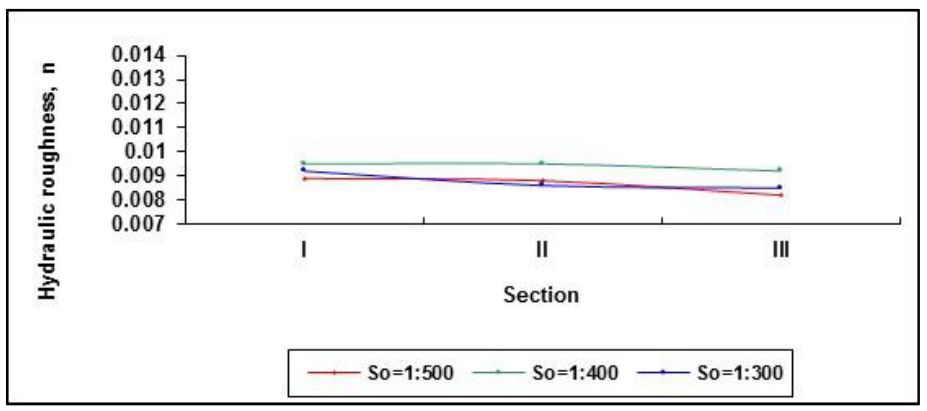

Fig. 4. Hydraulic roughness coefficient along three section with fixed discharges $0.025 \mathrm{~m}^{3} / \mathrm{s}$ in flume without gravel.

Table 1 showed the summary between hydraulic roughness, $\mathrm{n}$ according to fixed discharges and slopes along three sections of flume with gravel bed and without gravel bed. The average roughness coefficient, $\mathrm{n}$ yield from gravel bed ranging from 0.0090 to 0.0119 while the value of $n$, for flume without gravels range from 0.0082 to 0.0096 . It means that, the material of bed surface; gravel gave a resistance force to the flow as stated in [2].

Table 1. The average summary of roughness coefficient $\mathrm{n}$, according to fixed discharges and slopes (gravel bed)

\begin{tabular}{|c|c|c|c|c|c|c|c|}
\hline \multirow{3}{*}{ Slope } & $\begin{array}{c}\text { Controlled } \\
\text { Flow Rate } \\
\left(\mathrm{m}^{3} / \mathrm{s}\right)\end{array}$ & \multicolumn{3}{|c|}{$n$ values (gravel bed) } & \multicolumn{2}{c|}{$n$ values (without gravel bed) } \\
\cline { 3 - 8 } & $\begin{array}{c}\text { Section } \\
\text { I }\end{array}$ & $\begin{array}{c}\text { Section } \\
\text { II }\end{array}$ & $\begin{array}{c}\text { Section } \\
\text { III }\end{array}$ & $\begin{array}{c}\text { Section } \\
\text { I }\end{array}$ & $\begin{array}{c}\text { Section } \\
\text { II }\end{array}$ & $\begin{array}{c}\text { Section } \\
\text { III }\end{array}$ \\
\hline \multirow{3}{*}{$1: 500$} & 0.020 & 0.0092 & 0.0101 & 0.0094 & 0.0092 & 0.0088 & 0.0084 \\
\cline { 2 - 8 }$(0.002)$ & 0.025 & 0.0093 & 0.0099 & 0.0092 & 0.0089 & 0.0088 & 0.0082 \\
\cline { 2 - 8 } & 0.030 & 0.0093 & 0.0092 & 0.0086 & 0.0088 & 0.0087 & 0.0084 \\
\cline { 2 - 8 } & 0.035 & 0.0090 & 0.0094 & 0.0087 & 0.0088 & 0.0087 & 0.0082 \\
\hline \multirow{3}{*}{$1: 400$} & 0.020 & 0.0102 & 0.0105 & 0.0102 & 0.0096 & 0.0094 & 0.0095 \\
\cline { 2 - 8 }$(0.0025)$ & 0.025 & 0.0101 & 0.0105 & 0.0102 & 0.0095 & 0.0095 & 0.0092 \\
\cline { 2 - 8 } & 0.030 & 0.0100 & 0.0103 & 0.0097 & 0.0096 & 0.0092 & 0.0089 \\
\hline \multirow{3}{*}{$1: 300$} & 0.035 & 0.0100 & 0.0101 & 0.0098 & 0.0092 & 0.0093 & 0.0088 \\
\cline { 2 - 8 }$(0.0033)$ & 0.020 & 0.0116 & 0.0117 & 0.0107 & 0.0093 & 0.0087 & 0.0088 \\
\cline { 2 - 8 } & 0.025 & 0.0113 & 0.0119 & 0.0110 & 0.0092 & 0.0086 & 0.0085 \\
\cline { 2 - 8 } & 0.030 & 0.0112 & 0.0113 & 0.0107 & 0.0086 & 0.0086 & 0.0082 \\
\hline
\end{tabular}




\subsection{Froude Number, $\mathrm{Fr}$}

To classify the type of flow in the channel, the mean velocity for a given discharge must be determined first. For calculation of Froude number, $F_{R}$ is given from equation (2):

$$
F_{R}=\frac{v}{\sqrt{g D}}
$$

With $\mathrm{V}$ for mean velocity $(\mathrm{m} / \mathrm{s})$, $\mathrm{g}$ is gravitational acceleration $\left(\mathrm{m} / \mathrm{s}^{2}\right)$ and $\mathrm{D}$ is the hydraulic depth. Table 2 shows tabulated Froude number calculated from an average depth of each section in the flume and average velocity measured from experiment according to flow rates and bed slope of 1:500, 1:400 and 1:300 respectively. The flow measurement on the gravel and without gravel are in a subcritical state with Froude number, $\mathrm{Fr}=0.781$ to 0.888 and $\mathrm{Fr}=0.799$ to 0.902 . Froude number increased when slope increases.

Table 2. Froude number calculated from two different bed surfaces

\begin{tabular}{|c|c|c|c|}
\hline \multirow{3}{*}{ Slope } & Qexperiment $\left(\mathrm{m}^{3} / \mathrm{s}\right)$ & $\begin{array}{c}\text { Fr } \\
\text { (gravel) }\end{array}$ & $\begin{array}{c}\text { Fr } \\
\text { (without gravel) }\end{array}$ \\
\hline \multirow{3}{*}{$\begin{array}{c}1: 500 \\
(0.002)\end{array}$} & 0.020 & 0.781 & 0.799 \\
\cline { 2 - 4 } & 0.025 & 0.788 & 0.799 \\
\cline { 2 - 4 } & 0.030 & 0.802 & 0.782 \\
\hline \multirow{3}{*}{$1: 400$} & 0.035 & 0.819 & 0.775 \\
\cline { 2 - 4 }$(0.0025)$ & 0.020 & 0.836 & 0.813 \\
\cline { 2 - 4 } & 0.025 & 0.826 & 0.821 \\
\cline { 2 - 4 } & 0.030 & 0.835 & 0.818 \\
\hline \multirow{3}{*}{$(0.30033)$} & 0.035 & 0.852 & 0.822 \\
\cline { 2 - 4 } & 0.020 & 0.799 & 0.888 \\
\cline { 2 - 4 } & 0.025 & 0.828 & 0.879 \\
\cline { 2 - 4 } & 0.030 & 0.882 & 0.902 \\
\hline
\end{tabular}

\section{Conclusion}

The experimental work was accompanied to study the hydraulic roughness characteristics in an open channel with two bed surfaces. As conclusion, flow rate and roughness coefficient were influenced by bed roughness. For fixed bed material (with gravel and without gravel), the hydraulic roughness coefficient was influenced by the discharges. Bed surface without gravel also affects the differences between $Q_{\text {theory }}$ and $Q_{\text {experiment }}$ because of the bed material. It was found that gravel has more effect at steeper slope although this study was done in a small scale.

The authors gratefully acknowledge to University Tun Hussein Onn Malaysia and Ministry of Higher Education for sponsoring this research (FRGS Vot: 1414).

\section{References}

1. R.H. French, Open Channel Hydraulics, (Mc Graw-Hill Book Company,New York 1987)

2. V.T. Chow, Open Channel Hydraulics, (Mc Graw-Hill Book Company, New York 1959) 
3. J.M. Buffington, D.R. Montgomery, Water Resour. Res., 35(11), 3507 (1999)

4. K. Subramaya, Flow in Open Channel $2^{\text {nd }} E d$., (New Delhi. Mc Graw-Hill Companies Ltd. 1997)

5. B.J. McKeon, Proceeding of the Summer Program, Center for Turbulent Research, (2008)

6. Wang Xi, Sun Yi, Weizhen Lu, Wang Xiekang, J. Hydrology. Engr., 16(9), 710 (2011)

7. J.T. Limerinos, Dept. of Water Resources, (1970) 